\title{
Performance Testing of Light Pipes in Real Weather Conditions for a Confrontation with Hemera
}

\author{
B. Malet-Damour, H. Boyer, S. Guichard, and F. Miranville
}

\begin{abstract}
Daylight offers many possibilities. Its proper use is a major asset to develop the design, energy and environmental quality of a building but also improve the physiological and psychological conditions of the user. New emerging devices, offer the opportunity to improve visual comfort while, providing energy savings. The light pipes are considered as a part of these innovative devices. Existing semi-empirical models do not adequately transcribe the behavior of light pipes. The scientific objective of this study is to investigate the propagation of light within a real test-cell equipped with this device in real weather conditions. The aim is to better understand the role of each parameter (solar geometry, diffuse illumination, direct illumination, etc.). The results indicated a difference in light distribution within the test cell between the clear and overcast sky. We target new parameters to take into account in modeling the phenomenon.
\end{abstract}

Index Terms - Light pipe MLP, Hemera, daylighting analysis, experimental measurement.

\section{INTRODUCTION}

A light pipe refers to an overhead opening, which allows daylight to pass through a pipe (often mistakenly called skylight). It is innovative device able to transport and distribute natural light without heat transfer in dark rooms, different from traditional openings, and minimize the loss of light. This system is made of a dome placed on the roof, a highly reflective tube walls (greater than 99\%), and a diffuser. The dome should be shockproof and UV resistant. It protects the tube from dust and rain. The device can be coupled with an optical device to capture and redirect the sky radiation inside the tube. SOLATUBE® in Australia patented this concept in 1986.

The work described, in this publication is part of the research related to the study of complex lighting systems and, only apply to Tubular vertical light guides [1]-[3].

The main objectives of this paper are, to present the first results of an experimental analysis carried out with the aim of evaluating the performance of the Mirrored Light Pipe (MLP) used, and to compare with light levels set by the Commission Internationale de l'Eclairage (CIE).

Manuscript received August 1, 2015; revised December 16, 2015.

B. Malet-Damour, H. Boyer, and F. Miranville are with the Physics and Mathematical Engineering Laboratory for Energy and Environment (PIMENT), University of La Reunion, France (e-mail: bruno.malet-damour@univ-reunion.fr,_harry.boyer@univ-reunion.fr, frederic.miranville@univ-reunion.fr).

S. Guichard is with the Research Institute of Science and Innovation Now (IRISE), CESI of La Reunion, France (e-mail: sguichard@ cesi.fr).

\section{LIGHT PIPES IN ARCHITECTURE}

When entering through the vertical windows, natural light provides illumination, whose values decrease as one move away from windows. This decay is characterized by a very rapid decrease in the illuminance near the openings, and then progressively slower as it moves away from the facade. In the case of office building, without partition, light inputs are suitable for a distance of $6 \mathrm{~m}$ from the front openings. Beyond this depth, light supplements should be considered, such as light pipes [4]. The light pipes are generally required in this case. They permit to overcome problems related to direct illumination (glare, sunspot) by providing a diffused light (in the case of a Lambertian diffuser). Thus, depending on the configuration and requirements in lighting level, several processes of light pipe exist. Among all the used most known devices, we can listed for example, pipes using diffusion lenses, prismatic pipes, solid core systems and the Mirror Light Pipe (MLP) [5]. The tube can be vertical or horizontal, with one or several diffusers. The pipe can be straight or have bends. In the case of our study, we shall focus on one of the most commonly used methods, in a standard configuration to be integrated into a building: a straight light pipe - type MLP — with a single diffuser.

\section{EXPERIMENTAL SET-UP}

\section{A. Description of Room}

The experimental cell LGI is located in Saint -Pierre (Reunion Island, France). With an area of $9 \mathrm{~m}^{2}$, the test cell looks like a classic piece type bedroom or office. The test building was built to experimentally validate of the physical models implemented in CODYRUN and ISOLAB [6]-[9]. The inner and outer walls are white (absorption coefficient of the inner surfaces is about $60 \%$ ). The roof is made of corrugated iron midnight blue. A light pipe is installed through the roof system (Fig. 1(a)). The ceiling, wherein the diffuser of the light pipe is installed, is horizontal. The dimensions of the building are shown in Fig. 1(b). The azimuth of the test cell with respect to geographic north is $9^{\circ}$.

The light pipe is the MLP (Mirrored Light Pipe) with a diameter of $250 \mathrm{~mm}$. The pipe length is $1400 \mathrm{~mm}$, and has an inclined portion near $20^{\circ}$. The reflection coefficient of the multilayer film is $99.7 \%$ [10].

\section{B. Description of the Building Environment}

The test cell is placed on the experimental platform of the PIMENT laboratory (located at 21190S, 55280E, and 70.40 $\mathrm{m}$ above sea level). The floor of the platform is made of grass, 
as a result, we made assume that the ground albedo is 0.70 approximately.

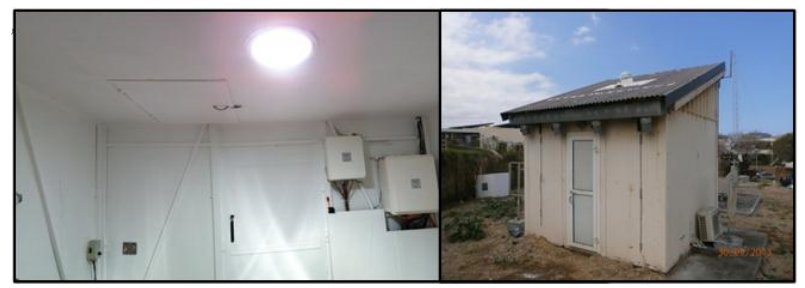

(a)
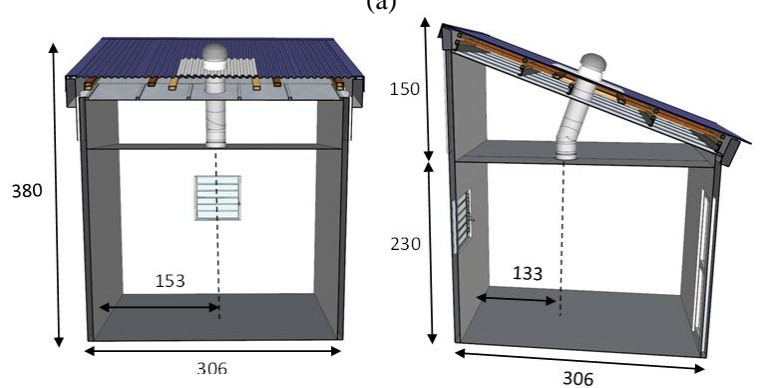

(b)

Fig. 1. (a) External and internal view of LGI cell test; (b) Dimensions of LGI cell test.

\section{Instrumentation and Experimental Procedure}

During the year, the meteorological station allows to get the real environment conditions by the recording data every minute. All measuring instruments are synchronized. An external luxmeter, measuring the global illumination, is installed on the weather station of the laboratory at a height of $2 \mathrm{~m}$. External luxmeter measuring the diffuse illumination is installed close to the meteorological station, and uses shading Shadeco ring, manufactured in the laboratory.

Within the test cell, nine luxmeters to quantify the penetration of daylight are used. Internal sensors are placed according to the arrangement of patterns in succession (Fig. 2) They are raised to $10 \mathrm{~cm}$ and are distributed in a hypothetical mesh.

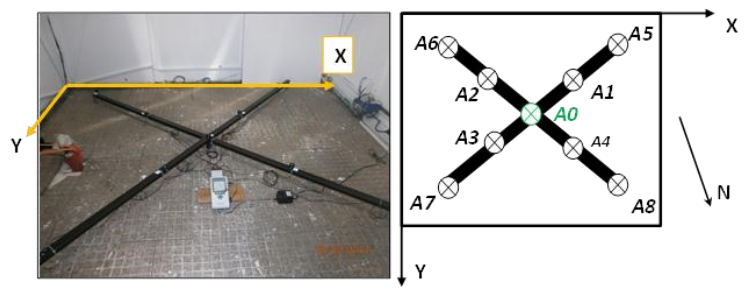

Fig. 2. Schematic position of the nine interior luxmeters.

\section{RESULTS AND DISCUSSION}

The experiment began in September 2013, winter in Reunion Island. Globally for this study, two categories of days are used as a reference experiment: it consists of clear day and overcast day conditions. The objective is to present the performance of light pipes in different type of sky, and understand the light distribution in the room. The results are presented in two parts: the first is to get the daily profile of the interior illumination as a function of outside global illumination. And the second is to study the light distribution inside the room. We also evaluated the daylight autonomy generated by the use of a light pipe according to the levels required by the CIE for three configuration types: an office, a classroom and a store. The standards (EN 12464-1 and ISO 8995/CIE 8008) recommend different levels of illumination depending on the area and type of use [11]. For an office and a basic activity (typing, reading, CAD post), the CIE recommends a minimum average illuminance of 500 lux. In a classroom, the illumination shall be 500 lux also. In a store, 300 lux must be maintained to ensure visual comfort.

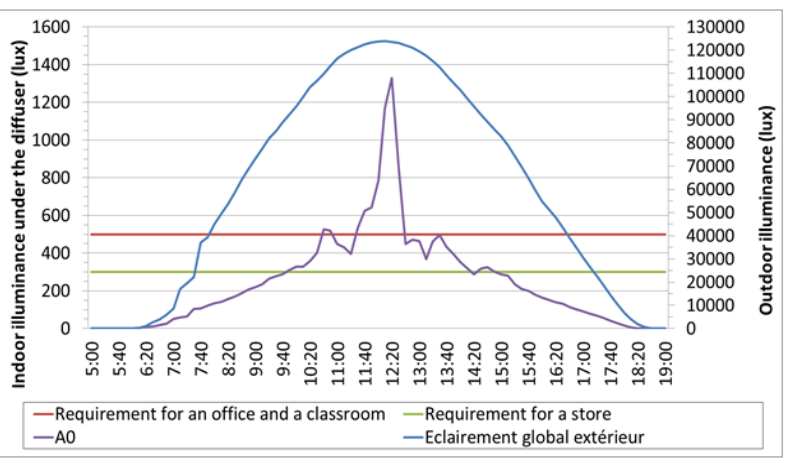

(a)

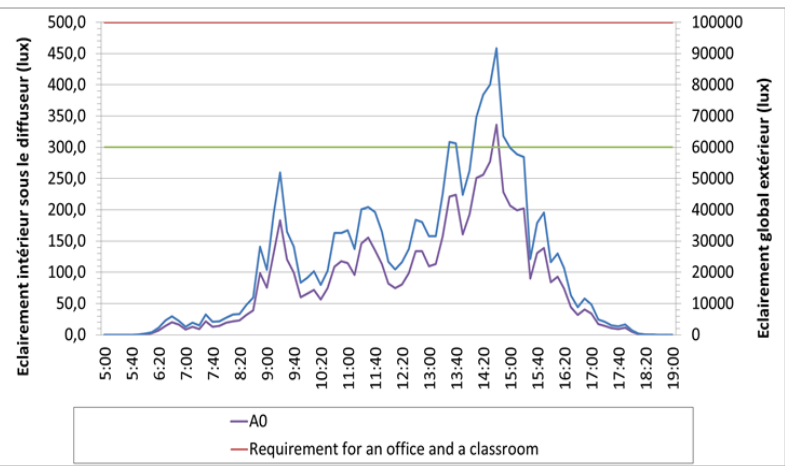

(b)

Fig. 3. (a) Indoor daylighting under the diffuser (A0) for clear sky conditions; (b) Indoor daylighting under the diffuser (A0) for overcast sky conditions.

\section{A. Results under Sunny Conditions}

During the day of October 3 (2013), there was clear sky. The maximum external global illumination reached 124 Klux at noon for a diffuse illumination of about 15 Klux. The maximum illumination under the diffuser is reach at 12:20 and is 1330 lux, with an average illuminance on the mesh of 370 lux.

The daily profile of the illumination at point $\mathrm{A} 0$ shows the direct impact of the dome: when the sun is at its zenith, the solar rays penetrate directly into the room, by limiting the number of reflection within the pipe (Fig. 3(a)). Otherwise, the illumination increases linearly until it reaches 400lux at 10:30. A linear decrease in the level of illumination is also observed from 2:40p.m.

Towards daylight autonomy, we take as reference levels requirement standards. On a clear sky day, the maximum illuminance on the working-plane amounted to 367 lux at $12: 20$, which is below the standard requirements for use in an office or a classroom (500 lux). The area under the diffuser of the light pipe can ignore the artificial lighting from 11:30 a.m. to $12: 30$ p.m. In the case of use for a sales area, the maximum illuminance is above the standard requirements (300lux). The area under the diffuser of the light pipe can ignore the artificial lighting from 9:50 a.m. to 2:50 p.m. or 5hours. 
The light distribution at different times makes it possible to understand the behavior of light in the room. During the day, the illumination is not uniform and isotropic (Fig. 4). As we saw with the daily illumination profiles at certain points of the grid, the light distribution seems to be directly related to the solar parameter (azimuth and solar altitude), especially if the sky is completely clear.

\section{B. Results under Cloudy Conditions}

During the day of October 1 (2013), there was an overcast sky. The maximum external global illumination reached 92 Klux at 2:40p.m. for a diffuse illumination of about 47 Klux. The maximum illumination under the diffuser is reached at 2:40p.m. and is 336 lux, with an average illuminance on the mesh of 223 lux. The daily profile of the illumination at point A0 clearly shows that the diffuse illumination is dominant against the direct illumination because the profile of the light under the diffuser follows the profile of the exterior lighting (Fig. 3(b)).
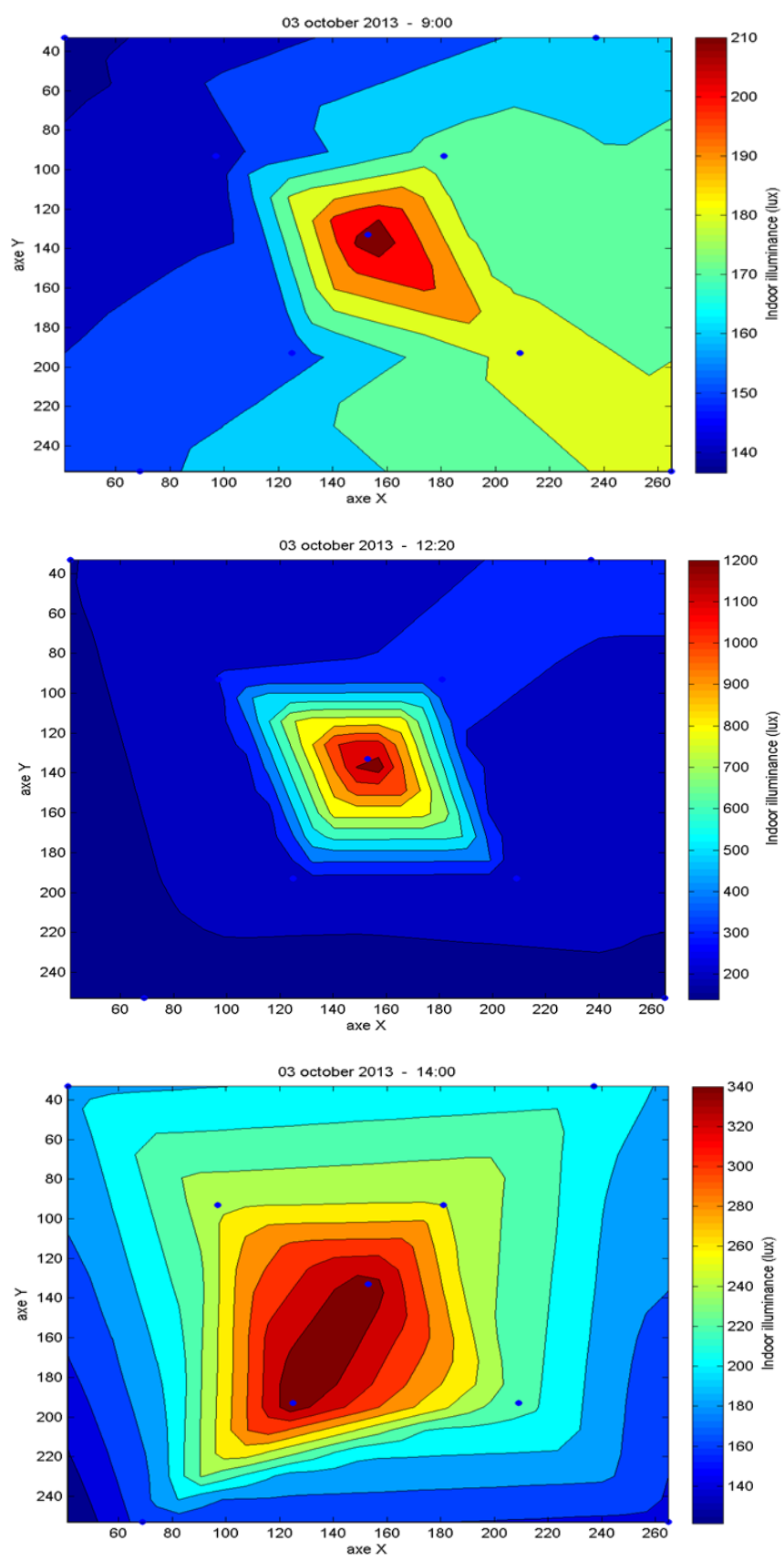

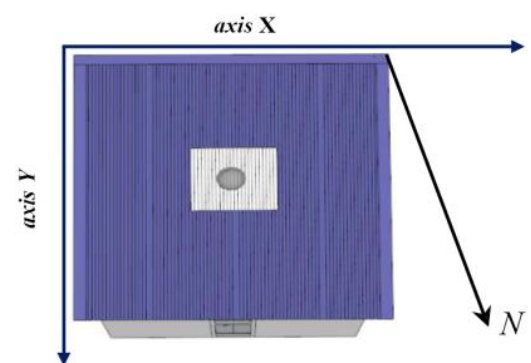

Fig. 4. Indoor daylighting repartition - October 3, 2013, sunny conditions.
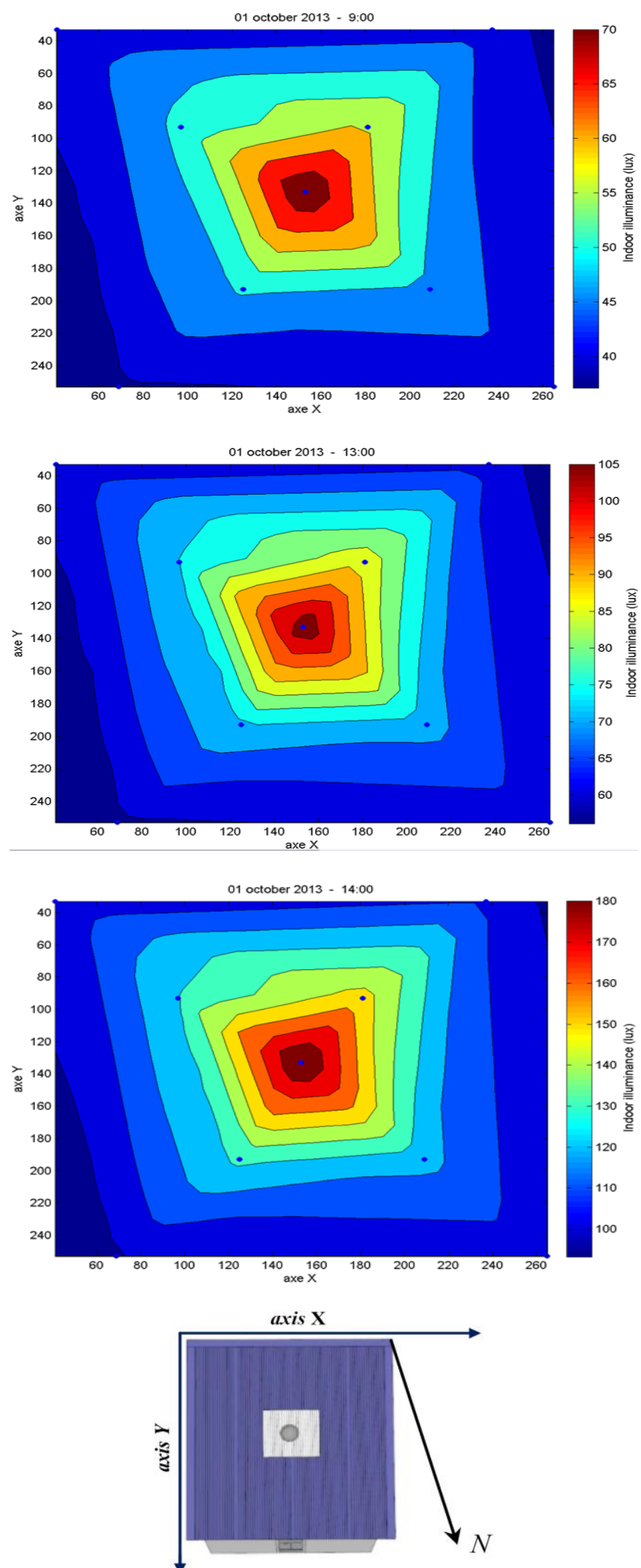

Fig. 5. Indoor daylighting repartition - October 1, 2013, cloudy conditions. 
Towards daylight autonomy, on an overcast sky day, the maximum illuminance on the working-plane amounted to 223 lux at 2:40p.m., which is below the standard requirements for use in an office or a classroom (500 lux) or in a store (300 lux). To respect the minimum requirements of the standards, a need of artificial lighting is required. The light distribution at different times, we can see that during the day, the illumination is not uniform and isotropic (Fig. 5). However, the impact of solar path on the light distribution is strictly limited because when it is not apparent (overcast, so no direct sunlight), light distribution in the room seems to be approaching a Lambertian distribution, unlike in clear sky conditions. All this confirms the daily illuminance profiles at certain points of the mesh.

\section{CONCLUSION AND PERSPECTIVES}

The study showed the actual performance of a light pipe (250mm diameter) during two days (clear and overcast sky). The results indicated a difference in light distribution within the test cell between the clear and overcast sky. We concluded that the external direct illumination (directly related to the solar geometry) had a substantial impact on this distribution. Furthermore, it is important to distinguish the type of lighting (direct or diffuse) in order to recreate the physical phenomenon in. This remark is a part of the current study initiated in the laboratory for the development of a model to predict the behavior of the light pipe [1], [2]. This will be integrated into a computer code, called Hemera, intended to simulate lighting environment.

In the second part of the study, we compared the experimental results with the standard requirements in terms of visual comfort, and for three use cases: an office, a classroom and a store. We found out that, for an experimental area of $9 \mathrm{~m}^{2}$, the chosen light pipe could achieve a level of demand during the day, mostly overcast. Daylight autonomy is impacted: only clear sky day can generate a range of up to 5 hours under the diffuser against one hour on average for the total area of the mesh. This study is not yet completed and, many configurations should be tested before drawing conclusions about, the actual performance of this device.

Perspectives of our study can be broken down as follows: experiment with the use of a deflector inside the dome; experiment with the use of black walls in the test cell; semi-empirical modeling of the phenomenon of propagation of light with a light pipe; developing a computer code dedicated to lighting technology (support for optimization and validation of the model).

\section{REFERENCES}

[1] B. Malet-Damour, H. Boyer, A. H. Fakra, and M. Bojic, "Light pipes performance prediction: Inter model and experimental confrontation on vertical circular light-guides," presented at the ISES World Solar Congress, Cancun, Mexique, 2013.

[2] B. Malet-Damour, "Les conduits de lumiere type MLP: Confrontation intermodele et experimentale," presented at the CIFEM 2014, 2014.

[3] H. Boyer, A. H. Fakra, F. Miranville, B. Malet-Damour, S. Guichard, and P. Lauret, "Evolution of CODYRUN from thermal simulation to coupled thermal and daylight simulation software.," in Proc. ISES Solar World Congress 2013.

[4] ADEME and CSTB, Construire avec la Lumière Naturelle, 2011

[5] V. G. Hansen, "Innovative daylighting systems for deep-plan commercial buildings," Ph.D. thesis, School of Design Queensland University of Technology, 2006.

[6] A. H. Fakra, F. Miranville, H. Boyer, and S. Guichard, "Development of a new model to predict indoor daylighting: Integration in CODYRUN software and validation," Energy Convers. Manag., vol. 52, no. 7, pp. 2724-2734, Jul. 2011.

[7] A. H. Fakra, H. Boyer, F. Miranville, and D. Bigot, "A simple evaluation of global and diffuse luminous efficacy for all sky conditions in tropical and humid climate," Renew. Energy, vol. 36, no. 1, pp. 298-306, Jan. 2011.

[8] H. Boyer, A. P. Lauret, L. Adelard, and T. A. Mara, "Building ventilation: A pressure airflow model computer generation and elements of validation," Energy Build., vol. 29, no. 3, pp. 283-292, Jan. 1999.

[9] S. Guichard, F. Miranville, D. Bigot, and H. Boyer, "A thermal model for phase change materials in a building roof for a tropical and humid climate: Model description and elements of validation," Energy Build., vol. 70, pp. 71-80, Feb. 2014.

[10] CSTB, "Solatube ${ }^{\circ}$ S160-DS, S290-DS et S330-DS - Conduit de lumière naturelle - Avis Technique 6/10-1836," Avis Technique Avis Technique 6/10-1836, 2011.

[11] LUX, "Eclairage public, Lieux de travail, Stades: Les normes européennes de l'éclairage," pp. 45-50, Mai/Juin 2004.

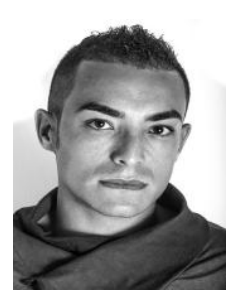

Bruno Malet-Damour comes from the Reunion Island, a French overseas department located in the Indian Ocean. He was born in the south of the island in July 1987, Bruno Malet-Damour realized all of his studies at University of La Reunion. He received a master degree in construction and environment in 2010, he worked as an engineer for research and development in a design firm in the field of sustainable development in Paris, France. Seduced by the research community, he reoriented his career to the development of a doctoral thesis in energy within the PIMENT laboratory. In parallel with this research, he is a teacher in physics at the Biological Engineering Department of the IUT of St Pierre, Reunion.

The search for Bruno Malet-Damour is a contribution to the study of Tubular Daylight Guidance Systems (TDGS). It follows four lines of study: experimentation, modelling, validation and application to engineering

$\mathrm{He}$ is also the author of computer code called Hemera. In 2014, he won the 3rd prize of an organized innovation competition at University of $\mathrm{La}$ Reunion. The same year, he received the award for best presentation for a special session at the ICRET Congress 2014 held in Hong Kong, China. Bruno Malet-Damour supports all collaborations in the framework of national, European or international. 